\title{
RESEARCH
}

Open Access

\section{Interstitial lung disease associated with adjuvant and neoadjuvant chemotherapy in early breast cancer}

Kenji Tezuka ${ }^{1 *} \mathbb{D}$, Kotaro Miura ${ }^{2}$, Yusuke Nakano ${ }^{3}$, Takahiro Ueda ${ }^{4}$, Kyoko Yagyu ${ }^{4}$, Shimako Matsuyama ${ }^{5}$, Masami Shirai ${ }^{5}$, Hiroshi Okuda ${ }^{6}$, Miho Ujikawa ${ }^{6}$ and Takayo Ota ${ }^{3^{*}}$ (D)

\begin{abstract}
Background: Interstitial lung disease (ILD) is a rare adverse event in patients receiving adjuvant or neoadjuvant chemotherapy (NAC) for breast cancer. Few studies have reported the frequency of ILD in detail, and only small numbers of cases have been described in the literature.

Given these previous findings concerning ILD, we retrospectively examined the clinicopathological characteristics of five cases of ILD who had received epirubicin and cyclophosphamide (EC) and compared their findings with nonILD cases.

Methods: The present single-center retrospective study included breast cancer patients who underwent adjuvant chemotherapy or NAC at our hospital between January 2014 and January 2021.

Results: Thirty-nine patients who had received EC for operable breast cancer were enrolled in this study. ILD developed 5 out of 39 patients (12.8\%). The incidence of ILD in patients with non-dose-dense (dd) or dd chemotherapy was statistically significantly different $(p=0.0149)$. ILD occurred in three patients during dd EC treatment and two during weekly paclitaxel (WPTX) after dd EC. ILD was detected in one patient with high Krebs von den Lungen-6 (KL-6) levels, in two patients with continuous pyrexia, and in two patients from computed tomography imaging, which was taken to estimate the efficacy of chemotherapy, in two patients. Three of the 5 ILD patients underwent bronchoalveolar lavage, and 2 of these patients were diagnosed with Pneumocystis jirovecii pneumonia (PCP). There were no cases of serious ILD that required steroid pulse therapy.
\end{abstract}

Conclusions: Dd chemotherapy may be associated with an increased ILD frequency, which may reflect developing PCP. Careful monitoring and a timely diagnosis are useful for detecting early-stage ILD.

Keywords: Breast cancer, Dose-dense chemotherapy, Interstitial lung disease, Pneumocystis jirovecii pneumonia

\footnotetext{
* Correspondence: tezuken@gmail.com; takayo.ota@gmail.com

'Department of Breast Surgery, Izumi City General Hospital, 4-5-1 Wake, Izumi, Osaka 594-0073, Japan

${ }^{3}$ Department of Medical Oncology, Izumi City General Hospital, 4-5-1 Wake, Izumi, Osaka 594-0073, Japan

Full list of author information is available at the end of the article
}

(c) The Author(s). 2021 Open Access This article is licensed under a Creative Commons Attribution 4.0 International License, which permits use, sharing, adaptation, distribution and reproduction in any medium or format, as long as you give appropriate credit to the original author(s) and the source, provide a link to the Creative Commons licence, and indicate if changes were made. The images or other third party material in this article are included in the article's Creative Commons licence, unless indicated otherwise in a credit line to the material. If material is not included in the article's Creative Commons licence and your intended use is not permitted by statutory regulation or exceeds the permitted use, you will need to obtain permission directly from the copyright holder. To view a copy of this licence, visit http://creativecommons.org/licenses/by/4.0/ The Creative Commons Public Domain Dedication waiver (http://creativecommons.org/publicdomain/zero/1.0/) applies to the data made available in this article, unless otherwise stated in a credit line to the data. 


\section{Background}

Interstitial lung disease (ILD) is a large heterogenous group of pulmonary diseases that involve the interstitium of the lungs $[1,2]$. Injury to the alveolar epithelial cells initiates an inflammatory response. Inflammatory cells activate fibroblasts in the interstitium, which damage the extracellular matrix permanently and prevent gas exchange in the lungs. The causes of ILD can be classified as idiopathic or non-idiopathic. Drug-induced interstitial lung disease (DILD) is one of the nonidiopathic ILDs.

In breast cancer patients receiving adjuvant or neoadjuvant chemotherapy (NAC), ILD is considered a rare adverse effect with a potentially fatal prognosis. Few studies have reported the frequency of ILD in detail, and only small numbers of cases have been described in the literature. In pivotal phase III clinical trials, with standard adjuvant chemotherapies, such as adriamycin and cyclophosphamide (AC) [3], epirubicin and cyclophosphamide (EC) [4], docetaxel and cyclophosphamide [5], or AC followed by paclitaxel or docetaxel [6], no ILDs were reported as adverse events, with the exception of one case of pneumonia in a patient who received EC [4]. Given these previous findings concerning ILD, we retrospectively examined the clinicopathological characteristics of five cases of ILD who had received EC and compared their findings with non-ILD cases.

\section{Methods}

The present single-center retrospective study included breast cancer patients who underwent adjuvant or NAC at our hospital between January 2014 and January 2021. The ethics committee of our institution approved this study.

The study protocol was approved by the Ethics Committee of Izumi City General Hospital (20-J17, 23 October 2020).

Age, estimated glomerular filtration rate (eGFR), smoking history (renal dysfunction and smoking history are known as a risk factor for ILD [7, 8]), stage, estrogen receptor (ER) status, progesterone receptor (PgR) status, human epidermal growth factor receptor 2 (HER2) overexpression, and menopausal status were studied as patient background and analyzed retrospectively. ER and PgR positive were defined as an expression by immunochemistry (IHC) in more than $10 \%$ of the cancer cells. HER2 overexpression was evaluated as positive by IHC with a score of $3+$ or $2+$ with a positive fluorescence in situ hybridization test.

The adjuvant or neoadjuvant chemotherapy regimens included tri-weekly or dose-dense (dd) chemotherapy, such as EC, or dd EC followed by weekly paclitaxel (wPTX) or triweekly docetaxel. NAC was administered when the clinicopathological risk was estimated high (e.g., tumors $\geq 2 \mathrm{~cm}$, hormone receptor negative, HER2 overexpression were existed). Since April 2018, we implemented the dd EC regimen, and administered especially if nodal status was positive, or hormone negative with high proliferative breast cancer.

Patients received four cycles of EC chemotherapy (E, 90 $\mathrm{mg} / \mathrm{m}^{2}$; C $600 \mathrm{mg} / \mathrm{m}^{2}$ ). Dd chemotherapy every 2 weeks 4 cycles of EC. All drugs were administered via intravenous infusion on day 1 of each cycle. Prophylactic pegfilgrastim $(3.6 \mathrm{mg}$ ) was administered via subcutaneous injection on day 3 for all dd regimens. Trastuzumab (HER) alone or in combination with pertuzumab (PER) was administered concurrently during wPTX or triweekly docetaxel in patients with the overexpression of HER2.

The diagnosis of ILD was made by computed tomography (CT). ILD was defined as an interstitial shadow on $\mathrm{CT}$, and was classified into four patterns according to previous reports [9]: (i) diffuse alveolar damage (DAD)-like pattern, (ii) chronic interstitial pneumonia-like pattern, (iii) eosinophilic pneumonia-like pattern, (iv) organizing pneumonia (OP)-like pattern, and (v) hypersensitivity reaction (HR)-like pattern.

Pneumocystis jirovecii pneumonia (PCP) was diagnosed with (i) positive polymerase chain reaction from bronchoalveolar lavage (BAL) and (ii) high serum $\beta$-D glucan levels.

Adverse events (AEs) were graded according to the common terminology criteria for adverse events 5.0 (CTCAE) [10]. The term "ILD" is considered to be in the same category as pneumonitis in the present report.

Comparisons between two groups were performed using Mann-Whitney test, Pearson's chi-square test, and Fisher's exact test. P values of $<0.05$ were considered to indicate statistical significance. Data were analyzed with using GraphPad Prism version 8 (La Jolla, CA, USA).

To examine a frequency of ILDs in published literatures, we reviewed literatures and pivotal clinical trials. Using the terms, "adriamycin," "epirubicin," "cyclophosphamide." "dose dense." "breast cancer," "interstitial lung disease," "pneumonitis." we searched PubMed up to 21 April 2021 to identify published articles on neoadjuvant/ adjuvant chemotherapies associated with ILD in early breast cancer. We included studies written in English. We excluded studies using other treatments, such as using liposomal doxorubicin or included radiotherapy. To review, we included papers reporting phase II or phase III clinical trials.

\section{Results}

\section{Patient characteristics}

Thirty-nine patients who had received EC for operable breast cancer were enrolled in this study. The characteristics of the patients are shown in Table 1. Five out of 39 patients developed ILD (12.8\%). The median ages of patients with and without ILD were 55 and 55 (range 38- 
Table 1 Patient characteristics with and without ILD $(n=39)$

\begin{tabular}{|c|c|c|c|}
\hline & With ILD $(n=5)$ & Without ILD $(n=34)$ & p value (b) $^{\text {b }}$ \\
\hline \multicolumn{4}{|l|}{ Age (years) } \\
\hline Median (range) & $55(38-63)$ & $55(29-74)$ & NS \\
\hline \multicolumn{4}{|l|}{ eGFR (mL/min) } \\
\hline Median (range) & 90 (60-95) & $79.5(48-120)$ & NS \\
\hline \multicolumn{4}{|l|}{ Smoking history } \\
\hline Yes & 0 & 4 & \\
\hline No & 5 & 30 & NS \\
\hline \multicolumn{4}{|l|}{ Stage } \\
\hline । & 0 & 7 & \\
\hline$\| \mathrm{A}$ & 2 & 13 & \\
\hline$\| B$ & 2 & 4 & \\
\hline$\| I I A$ & 1 & 6 & \\
\hline$\| I \mathrm{~B}$ & 0 & 1 & \\
\hline$\| I I C$ & 0 & 3 & NS \\
\hline \multicolumn{4}{|l|}{ Estrogen receptor ${ }^{\mathrm{a})}$} \\
\hline Positive & 4 & 20 & \\
\hline Negative & 1 & 14 & NS \\
\hline \multicolumn{4}{|c|}{ Progesterone receptor ${ }^{a)}$} \\
\hline Positive & 3 & 12 & \\
\hline Negative & 2 & 22 & NS \\
\hline \multicolumn{4}{|l|}{ HER 2 status } \\
\hline Positive & 0 & 15 & \\
\hline Negative & 5 & 19 & NS \\
\hline \multicolumn{4}{|l|}{ Menopausal status } \\
\hline Premenopausal & 1 & 13 & \\
\hline Postmenopausal & 4 & 21 & NS \\
\hline \multicolumn{4}{|c|}{ dd regimen administered } \\
\hline Yes & 5 & 13 & \\
\hline No & 0 & 21 & $<.05$ \\
\hline
\end{tabular}

ILD interstitial lung disease, eGFR estimated glomerular filtration rate, HER2 human epidermal growth factor receptor 2, dd dose-dense chemotherapy, NS not significant

${ }^{\mathrm{a}}$ Defined as an expression by immunochemistry in more than $10 \%$ of the cancer cells

${ }^{b}<0.05$ were considered to indicate statistical significance

Table 2 Administered regimens with and without ILD $(n=39)$

\begin{tabular}{lll}
\hline Administered regimen & With ILD & Without ILD \\
\hline EC only & 0 & 1 \\
EC followed by wPTX & 0 & 9 \\
dd EC only & 3 & 0 \\
dd EC followed by wPTX & 2 & 9 \\
EC followed by wPTX with HER & 0 & 6 \\
EC followed by triweekly docetaxel with HER & 0 & 1 \\
EC followed by wPTX with HER and PER & 0 & 4 \\
ddEC followed by wPTX with HER & 0 & 1 \\
ddEC followed by wPTX with HER and PER & 0 & 3 \\
\hline
\end{tabular}

ILD interstitial lung disease, $E$ epirubicin, $C$ cyclophosphamide, wPTX weekly paclitaxel, $d d$ dose dense, HER trastuzumab, PER pertuzumab
63 and 29-74) years, respectively. None of the enrolled patients with ILD had a history of smoking. There were no marked differences in the eGFR value, hormonal, HER2, or menopausal statuses of the groups, whereas the incidence of ILD in patients with non-dd or dd chemotherapy was statistically significantly different $(p=$ 0.0149). Five of the $18(27.8 \%)$ patients who received dd EC developed ILD.

\section{Incidence and characteristics of ILD}

Regimens stratified by the presence of ILD are shown in Table 2. ILD occurred in three patients during dd EC and two during wPTX after dd EC. 
Table 3 Clinical characteristics and outcomes of 5 patients with ILD $(n=5)$

\begin{tabular}{|c|c|c|c|c|c|c|c|}
\hline Case & Diagnostic opportunity & $\mathrm{SpO2}^{\mathrm{a})}(\%)$ & $\mathrm{KL}-6^{\mathrm{a})}(\mathrm{U} / \mathrm{mL})$ & Grade $^{\text {b) }}$ & CT findings & BAL and its diagnosis & Therapy for ILD \\
\hline 1 & Continuous pyrexia & 97 & 316 & 2 & $H R$ & Done, PCP & $P S L+T M P / S M X$ \\
\hline 2 & Continuous pyrexia & 98 & 468 & 1 & $H R$ & Done, Negative & None \\
\hline 3 & High KL-6, low SpO2 & 94 & 716 & 2 & $H R$ & None & PSL \\
\hline 4 & $\mathrm{E}-\left(\mathrm{CT}^{\mathrm{c}}\right.$, low SpO2 & 94 & 338 & 2 & OP & None & PSL \\
\hline 5 & $\mathrm{E}-\mathrm{CT}$ & 98 & 346 & 2 & $H R$ & Done, PCP & TMP/SMX \\
\hline
\end{tabular}

ILD interstitial lung disease, SpO2 percutaneous oxygen saturation, KL-6 serum Krebs von den Lungen-6, $C T$ computed tomography, BAL bronchoalveolar lavage sampling, HR hypersensitivity reaction-like pattern, PCP Pneumocystis jiroveci pneumonia, PSL orally prednisolone (a day), TMP/SMX orally trimethoprimsulfamethoxazole (a day), OP organizing pneumonia-like pattern

${ }^{a}$ Values were at the onset of ILD. Standard value; SpO2 $\geq 95 \%, \mathrm{KL}-6<500 \mathrm{U} / \mathrm{mL}$

${ }^{\mathrm{b}}$ ILD (pneumonitis) grade as in common terminology criteria for adverse events 5.0

${ }^{\mathrm{c}} \mathrm{CT}$ to estimate the anti-cancer effect after epirubicin and cyclophosphamide

The clinical characteristics and outcomes of the five patients with ILD are shown in Table 3. ILD was detected in one patient with high Krebs von den Lungen-6 (KL-6) levels, two with continuous pyrexia, and two by performing $\mathrm{CT}$ to estimate the anti-cancer effect after EC. Case numbers 3 and 4 in Table 3 were accompanied by a low level of percutaneous oxygen saturation. All patients were considered to have grade 1 or 2 ILD. One patient recovered with drug withdrawal alone. No patients required the administration of intravenous steroid pulse therapy.

Four of the five patients showed an HR-like CT pattern. Representative CT images are shown in Fig. 1. No patients showed any obvious findings on chest X-ray, whereas CT showed bilateral diffuse ground-glass opacity.
Three of the 5 ILD patients underwent BAL, 2 of these patients were diagnosed with $\mathrm{PCP}$ and were orally treated with trimethoprim-sulfamethoxazole $(720 \mathrm{mg}$ and $3600 \mathrm{mg}$, respectively, daily). BAL culturing revealed that the remaining one was negative for $P$. jiroveci and Mycoplasma. Candida antigen was not measured in any cases because they were judged to have mild ILD based on CT.

Regarding the subsequent clinical course, case 3 discontinued preoperative chemotherapy, and then operations were performed after they had recovered from ILD. Cases 1, 4, and 5 resumed wPTX postoperatively after preoperative EC and surgery. Case 2 developed ILD during preoperative wPTX and also recovered with drug withdrawal alone and resumed the administration of the remaining paclitaxel prior to surgery.

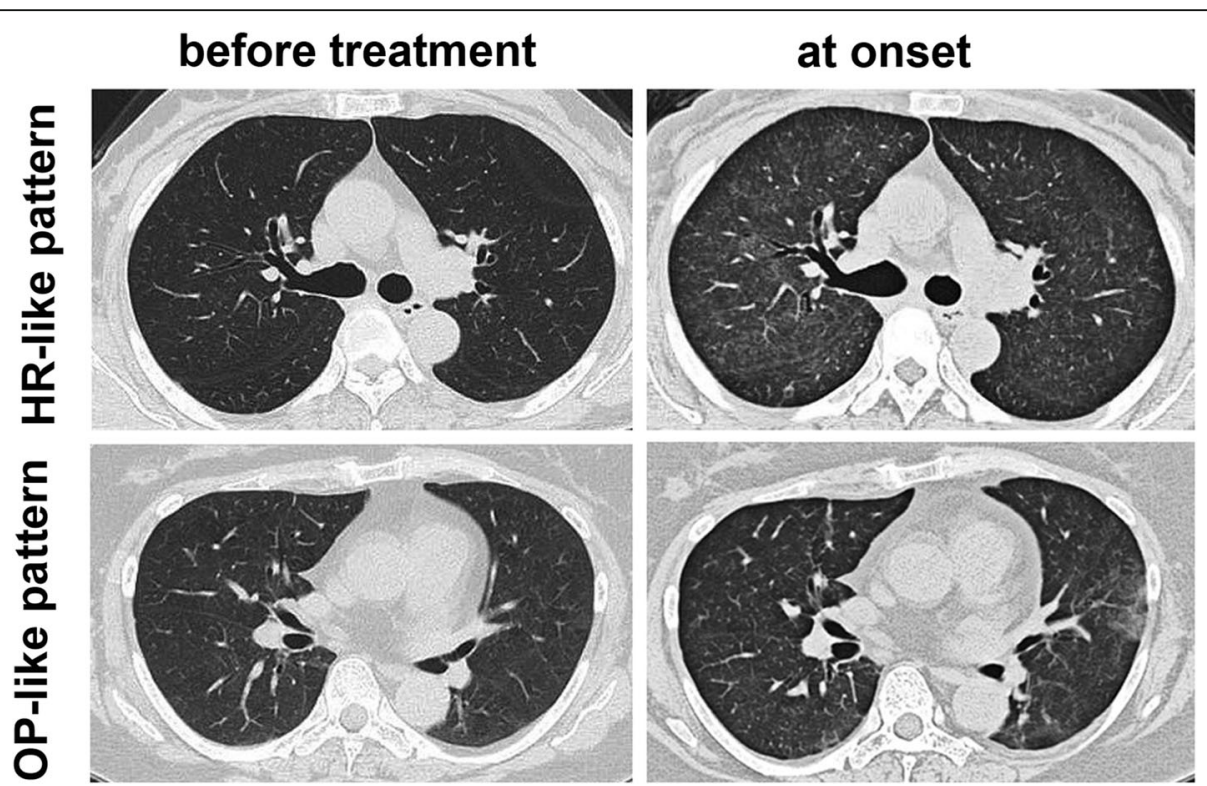

Fig. 1 Computed tomography of the chest before neoadjuvant chemotherapy and at the onset of interstitial lung disease in a 63-year-old female (with a hypersensitivity reaction-like pattern similar to that seen in case number 3 ) and in a 57-year-old female (with an organizing pneumonialike pattern similar to that seen in case number 4) 


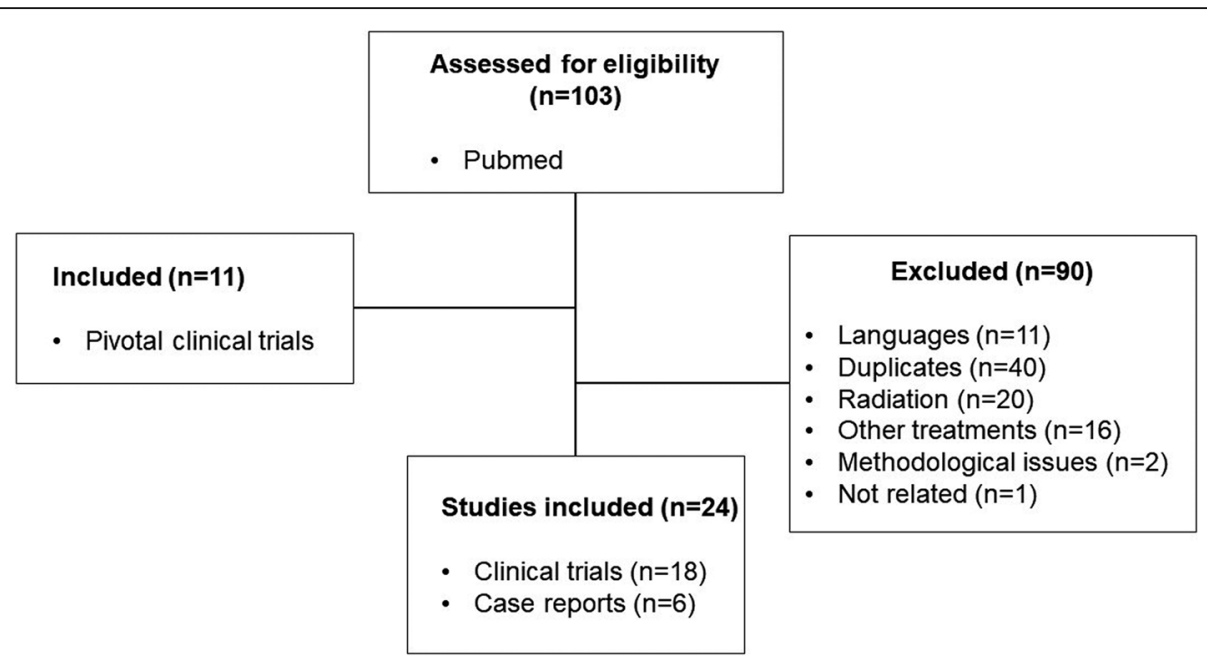

Fig. 2 Consort diagram for the literature search

Following the strategies to examine ILD cases in the literature, we retrieved 18 clinical trials and 6 case reports from PubMed (Fig. 2). The result of reviewing literatures is summarized as Table 4 [3-6, 11-30].

In phase II or phase III clinical trials, $55.6 \%$ of publications (10 out of 18) did not assess ILDs. In ILDreported clinical trials, all except two publications reported less than $1 \%$ of incidence. As case reports, 13 cases were identified in our literature search.

\section{Discussion}

Dd chemotherapy has been popular since it was introduced in the early 2000s and is now a standard treatment for patients with high-risk breast cancer, as several randomized controlled studies have revealed that its survival benefits are superior to those of standard chemotherapy [11, 20, 22]. In three phase III trials, in adjuvant settings, ILDs were not reported in either the dd or control groups [11, 14, 19]. In these trials, doxorubicin, cyclophosphamide followed by docetaxel [11], or fluorouracil, epirubicin, and cyclophosphamide (FEC) [14], or FEC or EC followed by paclitaxel [19] were administered for chemotherapy. In contrast, in a phase II trial of dd FEC followed by weekly alternate taxane treatment (paclitaxel or docetaxel) as adjuvant therapy, 4 of 44 patients (9\%) developed ILD (pneumonitis) during dd FEC [12], and in a Brazilian population, the frequency of ILD in patients who received wPTX $\left(80 \mathrm{mg} / \mathrm{m}^{2}\right)$ was as high as $4.2 \%$ [31].

In the case of HER2-positive breast cancer, no cases of ILD were reported in a phase II trial of EC followed by PTX and HER [16]. In the B-31 trial, which investigated AC followed by PTX and HER, 4 of 864 patients developed ILD, one of whom died. In the N9381 trial, 5 of 814 patients in the trastuzumab group developed grade
3 ILD or pulmonary infiltration, one of whom died [13]. In patients who received HER and PER in addition to several adjuvant regimens, only grade 3 adverse events were reported; none of these patients developed ILD [21]. The incidence of ILDs in this study was approximately $13 \%$ and tended to be higher in patients who received a dd regimen. Although this incidence was relatively high in comparison to previously reported studies, all patients developed grade 1 or 2 ILD and recovered without intravenous steroid pulse therapy.

It is difficult to determine the culprit of ILDs in patients who receive multiple drugs simultaneously. Any drugs are capable of inducing ILDs; however, reports of FEC- or EC-related ILDs are very rare in the relevant literature. Paclitaxel-induced ILDs are also rare, with a reported incidence of $0.7-12 \%[28,32]$. In the present study, ILDs were identified during dd EC as well as during PTX following dd EC. Both agents might be responsible for DILDs.

Dd chemotherapy increases the incidence of PCP, one of representative causes of ILD. PCP has been reported in several patients receiving dd chemotherapy for early breast cancer [30, 33]. In a large cohort study, the overall incidence of PCP among 2057 patients treated with dd AC was $0.6 \%$, whereas no PCP was diagnosed in 1001 patients treated with non-dd AC [18]. The total dose of steroids (as prophylaxis against nausea during the administration of AC) over 8 weeks of dd chemotherapy in comparison to 12 weeks of standard chemotherapy might explain the increased incidence of PCP [18]. In the present study, 5 out of 18 (27.8\%) patients developed ILDs with dd chemotherapy. We also identified two cases of PCP in patients who received dd chemotherapy. We used dexamethasone (4 mg, twice daily) on days $2-$ 3 , which might have influenced the rate of PCP 
Table 4 ILD associated with neo/adjuvant AC or (F)EC chemotherapy in early breast cancer

\begin{tabular}{|c|c|c|c|c|}
\hline Chemotherapy & Author & Year & ILD & Cause \\
\hline \multicolumn{5}{|l|}{ Clinical trials } \\
\hline$A C$ & Fisher $B$ et al. [3] & 1990 & NA & \\
\hline EC & Fisher B et al. [4] & 2001 & NA & \\
\hline $\mathrm{AC} \rightarrow \mathrm{T}, \mathrm{ddAC} \rightarrow \mathrm{T}$ & Citron ML et al. [11] & 2003 & NA & \\
\hline ddFEC & Dang CT et al. [12] & 2004 & $9 \%$ & \\
\hline $\mathrm{AC} \rightarrow \mathrm{T}$ vs $\rightarrow \mathrm{TH}$ & Romond EH et al. [13] & 2005 & $0 \%$ vs $0.4 \%, 0.6 \%$ & \\
\hline FEC & Venturini $\mathrm{M}$ et al. [14] & 2005 & $0 \%$ & \\
\hline ddFEC & Venturini $\mathrm{M}$ et al. [14] & 2005 & $<1 \%$ & \\
\hline$A C$ & Jones SE et al. [5] & 2006 & NA & \\
\hline$A C \rightarrow T$ & Sparano JA et al. [6] & 2008 & $<0.5 \%$ & \\
\hline $\mathrm{ddEC} \rightarrow \mathrm{T}$ & Dang C et al. [15] & 2008 & $0 \%$ & \\
\hline $\mathrm{EC} \rightarrow T$ vs EC $\rightarrow \mathrm{TH}$ & Shimizu et al. [16] & 2010 & NA & \\
\hline $\mathrm{T} \rightarrow \mathrm{FEC}$ & Gonzalez-Angulo AM et al. [17] & 2014 & $0 \%$ & \\
\hline $\mathrm{AC} \rightarrow \mathrm{T}$ VS $\rightarrow \mathrm{TH}$ & Waks AG et al. [18] & 2015 & $0 \%$ vs $0 \%$ & \\
\hline $\mathrm{ddAC} \rightarrow \mathrm{T}$ vs $\rightarrow \mathrm{TH}$ & Waks AG et al. [18] & 2015 & $0 \%$ vs $0.6 \%$ & PCP \\
\hline $\mathrm{dd}(\mathrm{F}) \mathrm{EC} \rightarrow \mathrm{T},(\mathrm{F}) \mathrm{EC} \rightarrow \mathrm{T}$ & Del Mastro L et al. [19] & 2015 & NA & \\
\hline $\mathrm{ddEC} \rightarrow \mathrm{D}, \mathrm{FEC}$ & Foukakis T et al. [20] & 2016 & NA & \\
\hline$(\mathrm{F}) \mathrm{AC},(\mathrm{F}) \mathrm{EC} \rightarrow \mathrm{TH}, \mathrm{DH}$ vs $(\mathrm{F}) \mathrm{AC},(\mathrm{F}) \mathrm{EC} \rightarrow \mathrm{THP}$ or DHP & von Minckwitz G et al. [21] & 2017 & NA & \\
\hline $\mathrm{AC}, \mathrm{EC} \rightarrow \mathrm{DC} \mathrm{C}^{\prime} \mathrm{v}$ v $\mathrm{AC}, \mathrm{EC} \rightarrow \mathrm{DC} \mathrm{C}^{\prime} \mathrm{HP}$ & von Minckwitz G et al. [21] & 2017 & NA & \\
\hline $\mathrm{ddAC}, \mathrm{ddEC} \rightarrow T$ & Takabatake D et al. [22] & 2018 & NA & \\
\hline $\mathrm{ddEC} \rightarrow$ Next treatment & Morita S et al. [23] & 2018 & $3.9 \%$ & PCP \\
\hline nab-PTX $\rightarrow F E C$ & Kin T et al. [24] & 2020 & NA & \\
\hline \multicolumn{5}{|l|}{ Case reports } \\
\hline$d d A C$ & Tolaney SM et al. [25] & 2006 & 1 case & PCP \\
\hline dd (detailed regimen, not mentioned) & Tolaney SM et al. [25] & 2006 & 1 case & PCP \\
\hline $\mathrm{FEC} \rightarrow \mathrm{T}$ & Kawajiri $\mathrm{H}$ et al. [26] & 2013 & 5 cases & \\
\hline FEC & Shinohara A et al. [27] & 2013 & 1 case & PCP \\
\hline $\mathrm{dd} A C \rightarrow T$ & Bielopolsky D et al. [28] & 2017 & 3 cases & \\
\hline $\mathrm{EC} \rightarrow \mathrm{H}$ & Sugaya A et al. [29] & 2017 & 1 case & \\
\hline $\mathrm{ddAC}$ & Khoo C et al. [30] & 2019 & 1 case & PCP \\
\hline
\end{tabular}

Abbreviations: $A$ doxorubicin, $E$ epirubicin, $C$ cyclophosphamide, $C$ carboplatin, $D$ docetaxel, $d d$ dose-dense, $F$ fluorouracil, $H$ trastuzumab, $I L D$ interstitial lung disease, NA not assessed, $P C P$ pneumocystis jirovecii pneumonia, $T$ paclitaxel, $T H$ paclitaxel and trastuzumab, $T H P$ paclitaxel, trastuzumab, and pertuzumab

infection. It is important to obtain BAL samples to distinguish DILD from PCP.

In most cases of DILD, CT findings are characterized by a bilateral diffuse, extensive patchy, reticular, or ground-glass appearance, with a pattern of infiltration. Fatal lung disorders commonly have a DAD-like pattern, and the prognosis is poor, regardless of the drug that is used [7-9]. In contrast, almost all of our cases showed an HR-like pattern, which manifests as bilateral diffuse ground-glass opacity, responds well to steroid treatment, and has a good prognosis [7-9]. In the present study, we performed close monitoring of clinical findings, such as a continuous fever and KL-6 elevation, and CT imaging evaluation was proactively performed, which facilitated the early detection of ILD.
This study was limited by its retrospective nature and small population, which might have influenced on the incidence of ILD in our study. In addition, reporting methods of ILD may differ around the world [7]. Previous reports did not clarify whether or not PCP should be added as an ILD or pneumonitis and did not clearly distinguish between the two entities [12, 31]. If PCP had been excluded from ILD in our study, the ILD frequency in this study would have been a valid number.

In summary, we studied the clinical findings and imaging characteristics of ILD in early breast cancer patients receiving adjuvant or neoadjuvant chemotherapy. The incidence of ILD in the present study was relatively high; however, all cases were identified as mild ILDs. Dd 
chemotherapy increased the incidence of ILDs, partly because PCP cases were included. Proactively performing CT imaging evaluation might be useful for the early detection of ILD.

\begin{abstract}
Abbreviations
AC: Adriamycin and cyclophosphamide; AE: Adverse event;

BAL: Bronchoalveolar lavage; CT: Computed tomography; CTCAE: Common Terminology Criteria for Adverse Events; DAD: Diffuse alveolar damage; dd: Dose-dense; DILD: Drug-induced interstitial lung disease; EC: Epirubicin and cyclophosphamide; eGFR: Estimated glomerular filtration rate; ER: Estrogen receptor; FEC: Fluorouracil, epirubicin, and cyclophosphamide; HER: Trastuzumab; HER2: Human epidermal growth factor receptor 2; HR: Hypersensitivity reaction; IHC: Immunochemistry; ILD: Interstitial lung disease; KL-6: Krebs von den Lungen-6; NAC: Neoadjuvant chemotherapy; OP: Organizing pneumonia; PCP: Pneumocystis jirovecii pneumonia; PER: Pertuzumab; PgR: Progesterone receptor; wPTX: Weekly paclitaxel
\end{abstract}

\section{Acknowledgements}

Not applicable.

\section{Authors' contributions}

Kenji Tezuka conceived and designed the study. Kenji Tezuka, Kotaro Miura, and Takayo Ota drafted the manuscript. All authors involved in patient management read, critically reviewed, and approved the manuscript.

\section{Funding}

None.

\section{Availability of data and materials}

The datasets used and/or analyzed during the current study are available from the corresponding author on reasonable request.

\section{Declarations}

\section{Ethics approval and consent to participate}

This study was retrospective. Patients were not required to give their informed consent for the study. We used an opt-out method to obtain consent for the study using a website (https://izumi.tokushukai.or.jp/). The research protocol and the website were approved by the Institutional Review Board.

\section{Consent for publication}

Not applicable.

\section{Competing interests}

The authors declare that they have no competing interests.

\section{Author details}

'Department of Breast Surgery, Izumi City General Hospital, 4-5-1 Wake, Izumi, Osaka 594-0073, Japan. ${ }^{2}$ Department of Surgery, Izumi City General Hospital, 4-5-1 Wake, Izumi, Osaka 594-0073, Japan. ${ }^{3}$ Department of Medical Oncology, Izumi City General Hospital, 4-5-1 Wake, Izumi, Osaka 594-0073, Japan. ${ }^{4}$ Department of Respiratory Medicine, Izumi City General Hospital, 4-5-1 Wake, Izumi, Osaka 594-0073, Japan. ${ }^{5}$ Nursing Department, Izumi City General Hospital Izumi, 4-5-1 Wake, Izumi, Osaka 594-0073, Japan. ${ }^{6}$ Department of Pharmacy, Izumi City General Hospital, 4-5-1 Wake, Izumi, Osaka 594-0073, Japan.

Received: 21 February 2021 Accepted: 4 June 2021

Published online: 11 June 2021

\section{References}

1. Cosgrove GP, Schwarz MI. Approach to the evaluation and diagnosis of interstitial lung disease. In; Interstitial lung disease. 5th ed. Schwarz MI, King TE (eds): PMPH USA, Ltd. New Haven, CT, Kindle; 2019.

2. Gulati M. Diagnostic assessment of patients with interstitial lung disease. Prim Care Respir J. 2011;20(2):120-7. https://doi.org/10.4104/pcrj.2010.00079.

3. Fisher B, Brown AM, Dimitrov NV, Poisson R, Redmond C, Margolese RG, et al. Two months of doxorubicin-cyclophosphamide with and without interval reinduction therapy compared with 6 months of cyclophosphamide, methotrexate, and fluorouracil in positive-node breast cancer patients with tamoxifen-nonresponsive tumors: Results from the National Surgical Adjuvant Breast and Bowel Project B-15. J Clin Oncol. 1990;8(9):1483-96. https://doi.org/10.1200/JCO.1990.8.9.1483.

4. Fisher B, Anderson S, Tan-Chiu E, Wolmark N, Wickerham DL, Fisher ER, et al. Tamoxifen and chemotherapy for axillary node-negative, estrogen receptornegative breast cancer: Findings from National Surgical Adjuvant Breast and Bowel Project B-23. J Clin Oncol. 2001;19(4):931-42. https://doi.org/10.1200/ JCO.2001.19.4.931.

5. Jones SE, Savin MA, Holmes FA, O'Shaughnessy JA, Blum JL, Vukelja S, et al. Phase III trial comparing doxorubicin plus cyclophosphamide with docetaxel plus cyclophosphamide as adjuvant therapy for operable breast cancer. J Clin Oncol. 2006;24(34):5381-7. https://doi.org/10.1200/JCO.2006. 06.5391.

6. Sparano JA, Wang M, Martino S, Jones V, Perez EA, Saphner T, et al. Weekly paclitaxel in the adjuvant treatment of breast cancer. N Engl J Med. 2008; 358(16):1663-71. https://doi.org/10.1056/NEJMoa0707056.

7. Skeoch S, Weatherley N, Swift AJ, Oldroyd A, Johns C, Hayton C, et al. Druginduced interstitial lung disease: A systematic review. J Clin Med. 2018;7(10): 356. https://doi.org/10.3390/jcm7100356.

8. Camus P, Fanton A, Bonniaud P, Camus C, Foucher P. Interstitial lung disease induced by drugs and radiation. Respiration. 2004;71(4):301-26. https://doi.org/10.1159/000079633.

9. Kubo K, Azuma A, Kanazawa M, Kameda H, Kusumoto M, Genma A, et al. Japanese Respiratory Society Committee for formulation of Consensus statement for the diagnosis and treatment of drug-induced lung injuries: Consensus statement for the diagnosis and treatment of drug-induced lung injuries. Respir Investig. 2013;51(4):260-77. https://doi.org/10.1016/j.resinv.2 013.09.001.

10. Common terminology criteria for adverse events 5.0 (CTCAE). 2017.

11. Citron ML, Berry DA, Cirrincione C, Hudis C, Winer EP, Gradishar WJ, et al. Randomized trial of dose-dense versus conventionally scheduled and sequential versus concurrent combination chemotherapy as postoperative adjuvant treatment of node-positive primary breast cancer: First report of Intergroup Trial C9741/Cancer and Leukemia Group B Trial 9741. J Clin Oncol. 2003;21 (8):1431-9. https://doi.org/10.1200/JCO.2003.09.081.

12. Dang CT, D'Andrea GM, Moynahan ME, Dickler MN, Seidman AD, Fornier M, et al. Phase II study of feasibility of dose-dense FEC followed by alternating weekly taxanes in high-risk, four or more node-positive breast cancer. Clin Cancer Res. 2004;10(17):5754-61. https://doi.org/10.1158/1078-0432.CCR-040634

13. Romond EH, Perez EA, Bryant J, Suman VJ, Geyer CE Jr, Davidson NE, et al. Trastuzumab plus adjuvant chemotherapy for operable HER2-positive breast cancer. N Engl J Med. 2005;353(16):1673-84. https://doi.org/10.1056/NEJMoa 052122

14. Venturini M, Del Mastro L, Aitini E, Baldini E, Caroti C, Contu A, et al. Dosedense adjuvant chemotherapy in early breast cancer patients: results from a randomized trial. J Natl Cancer Inst. 2005;97(23):1724-33. https://doi.org/10.1 093/jnci/dji398.

15. Dang C, D'Andrea G, Lake D, Sugarman S, Fornier M, Moynahan ME, et al. Prolonged dose-dense epirubicin and cyclophosphamide followed by paclitaxel in breast cancer is feasible. Clin Breast Cancer. 2008;8(5):418-24. https://doi.org/10.3816/CBC.2008.n.050.

16. Shimizu T, Hirano A, Kamimura M, Ogura K, Kim N, Watanabe O, et al. A phase II study of epirubicin and cyclophosphamide followed by weekly paclitaxel with or without trastuzumab as primary systemic therapy in locally advanced breast cancer. Anticancer Res. 2010;30(11):4665-71.

17. Gonzalez-Angulo AM, Akcakanat A, Liu S, Green MC, Murray JL, Chen H, et al. Open-label randomized clinical trial of standard neoadjuvant chemotherapy with paclitaxel followed by FEC versus the combination of paclitaxel and everolimus followed by FEC in women with triple receptornegative breast cancert. Ann Oncol. 2014;25(6):1122-7. https://doi.org/10.1 093/annonc/mdu124.

18. Waks AG, Tolaney SM, Galar A, Arnaout A, Porter JB, Marty FM, et al. Pneumocystis jiroveci pneumonia (PCP) in patients receiving neoadjuvant and adjuvant anthracycline-based chemotherapy for breast cancer: Incidence and risk factors. Breast Cancer Res Treat. 2015;154(2):359-67. https://doi.org/10.1007/s10549-015-3573-2.

19. Del Mastro L, De Placido S, Bruzzi P, De Laurentiis M, Boni C, Cavazzini G, et al. Gruppo Italiano Mammella (GIM) investigators: Fluorouracil and dose-dense 
chemotherapy in adjuvant treatment of patients with early-stage breast cancer: An open-label, $2 \times 2$ factorial, randomised phase 3 trial. Lancet. 2015; 385(9980):1863-72. https:/doi.org/10.1016/50140-6736(14)62048-1.

20. Foukakis T, von Minckwitz G, Bengtsson NO, Brandberg Y, Wallberg B, Fornander T, et al. Swedish Breast Cancer Group (SweBCG), the German Breast Group (GBG), and the Austrian Breast \& Colorectal Cancer Study Group (ABCSG): Effect of tailored dose-dense chemotherapy vs standard 3weekly adjuvant chemotherapy on recurrence-free survival among women with high-risk early breast cancer: a randomized clinical trial. JAMA. 2016; 316(18):1888-96. https://doi.org/10.1001/jama.2016.15865.

21. von Minckwitz G, Procter M, de Azambuja E, Zardavas D, Benyunes M, Viale $G$, et al. APHINITY Steering Committee and Investigators: Adjuvant Pertuzumab and Trastuzumab in Early HER2-Positive Breast Cancer. N Engl J Med. 2017:377(2):122-31. https://doi.org/10.1056/NEJMoa1703643.

22. Takabatake D, Kajiwara Y, Ohtani S, Itano Y, Yamamoto M, Kubo S, et al. The efficacy and feasibility of dose-dense sequential chemotherapy for Japanese patients with breast cancer. Breast Cancer. 2018;25(6):717-22. https://doi. org/10.1007/s12282-018-0877-1.

23. Morita S, Kikumori T, Tsunoda N, Inaishi T, Adachi Y, Ota A, et al. Feasibility of dose-dense epirubicin and cyclophosphamide with subcutaneous pegfilgrastim $3.6 \mathrm{mg}$ support: a single-center prospective study in Japan. Int J Clin Oncol. 2018;23(1):195-200. https://doi.org/10.1007/s10147-017-1177-z.

24. Kin T, Ohtani S, Maeda R, Ueno A, Fujihara M, Takamatsu Y, et al. Nabpaclitaxel followed by 5 -fluorouracil, epirubicin and cyclophosphamide in neoadjuvant chemotherapy for resectable breast cancer: a phase II trial. World J Oncol. 2020;11(5):197-203. https://doi.org/10.14740/wjon1333.

25. Tolaney SM, Partridge AH, Sheib RG, Burstein HJ, Winer EP. Pneumocystis carinii pneumonia during dose-dense chemotherapy for breast cancer. J Clin Oncol. 2006;24(33):5330-1. https://doi.org/10.1200/JCO.2006.08.1083.

26. Kawajiri H, Takashima T, Onoda N, Kashiwagi S, Ishikawa T, Hirakawa K. Interstitial pneumonia associated with neoadjuvant chemotherapy in breast cancer. Mol Clin Oncol. 2013;1(3):433-6. https://doi.org/10.3892/mco.2013.87.

27. Shinohara T, Yasui M, Yamada H, Fujimori Y, Yamagishi K. Pneumocystis pneumonia during Postoperative Adjuvant Chemotherapy for Breast Cancer. Case Rep Oncol Med. 2013;2013:954346.

28. Bielopolski D, Evron E, Moreh-Rahav O, Landes M, Stemmer SM, Salamon F. Paclitaxel-induced pneumonitis in patients with breast cancer: Case series and review of the literature. J Chemother. 2017;29(2):113-7. https://doi.org/1 0.1179/1973947815Y.00000000029.

29. Sugaya A, Ishiguro S, Mitsuhashi S, Abe M, Hashimoto I, Kaburagi T, et al. Interstitial lung disease associated with trastuzumab monotherapy: a report of 3 cases. Mol Clin Oncol. 2017;6(2):229-32. https://doi.org/10.3892/mco.2 016.1113.

30. Khoo C, Gilchrist J, Williamson JP, Paul M, Kefford R. Pneumocystis jirovecii in a patient on dose-dense chemotherapy for early breast cancer. Respirol Case Rep. 2019;7:e00459.

31. Santana IA, Oliveira JA, da Silva Lima JM, Testa L, Piato JRM, Hoff PM, et al. Feasibility of two schedules of weekly paclitaxel in HER2-negative early breast cancer in a Brazilian community setting. Breast Cancer. 2016;23(2): 261-5. https://doi.org/10.1007/s12282-014-0564-9.

32. Khan A, McNally D, Tutschka PJ, Bilgrami S. Paclitaxel-induced acute bilateral pneumonitis. Ann Pharmacother. 1997;31(12):1471-4. https://doi.org/10.11 77/106002809703101205.

33. Watanabe H, Kitahara Y, Murakami Y, Nihashi F, Matsushima S, Eifuku T, et al. Pneumocystis jirovecii pneumonia in a patient with breast cancer receiving neoadjuvant dose-dense chemotherapy. Intern Med. 2020;59(7):987-90. https://doi.org/10.2169/internalmedicine.3907-19.

\section{Publisher's Note}

Springer Nature remains neutral with regard to jurisdictional claims in published maps and institutional affiliations.

Ready to submit your research? Choose BMC and benefit from:

- fast, convenient online submission

- thorough peer review by experienced researchers in your field

- rapid publication on acceptance

- support for research data, including large and complex data types

- gold Open Access which fosters wider collaboration and increased citations

- maximum visibility for your research: over $100 \mathrm{M}$ website views per year

At BMC, research is always in progress.

Learn more biomedcentral.com/submissions 